\title{
Rechtsgeschäftliche und gesetzliche Nutzungsrechte im Urheberrecht
}

Eine dogmatische Analyse der Rechtsnatur und der vertraglichen Gestaltungsmöglichkeiten

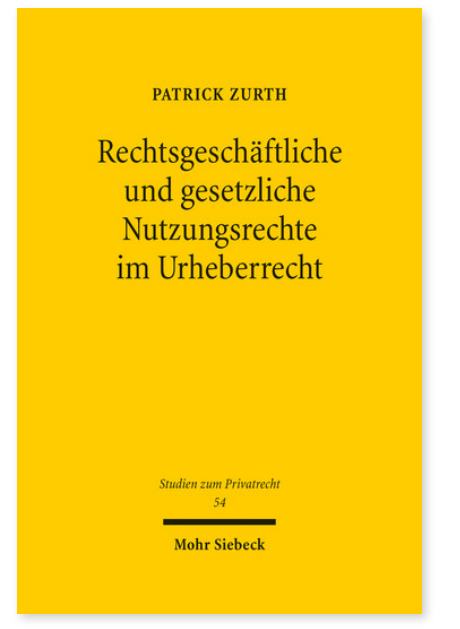

2016. XXIX, 383 Seiten. StudPriv 54

ISBN 978-3-16-154650-1

DOI 10.1628/978-3-16-154650-1

eBook PDF 109,00€

ISBN 978-3-16-154649-5

Leinen $109,00 €$
Patrick Zurth versucht, ein dogmatisches Fundament für die Verwertung und Nutzung urheberrechtlicher Werke zu errichten und das Urheberrecht als besonderes Privatrecht in die Dogmatik des allgemeinen Zivilrechts einzugliedern, um so eine kohärente und konsistente Rechtsordnung aufzuzeigen. Aus der bestehenden gesetzlichen Substanz soll eine Dogmatik entwickelt werden, die auf diese Weise die bestehenden gesetzlichen Lücken schließt und ein in sich geschlossenes System aufzeigt. Der Autor entwirft dabei nicht nur ein neues Verständnis der Lizenz ( $\$ 31$ UrhG) sondern auch der Schranken (§§ 44a ff. UrhG). Dies sind die beiden zentralen Rechtsinstrumente zur Nutzung urheberrechtlicher Werke. Er analysiert, inwiefern aus dieser Verwandtschaft der beiden Rechtsinstitute dogmatische Gemeinsamkeiten folgen und welche Unterschiede festzustellen sind.

Patrick Zurth Geboren 1987; Studium der Rechtswissenschaften an der Humboldt-Universität zu Berlin; 2012 Erste juristische Prüfung; 2013-16 wissenschaftlicher Mitarbeiter am Lehrstuhl für Bürgerliches Recht, Gewerblichen Rechtsschutz und Urheberrecht, Internationales Privatrecht und Rechtsvergleichung an der Humboldt-Universität zu Berlin; seit 2015 Rechtsreferendar am Kammergericht Berlin.
Jetzt bestellen:
https://mohrsiebeck.com/buch/rechtsgeschaeftliche-und-gesetzliche-nutzungsrechte-im-urheberrecht-9783161546501?
no_cache=1
order@mohrsiebeck.com
Telefon: +49 (0)7071-923-17
Telefax: +49(0)7071-51104 